\title{
A DISCUSSIOH ON THE LAYOUT OF
}

\author{
EI,FNENTS ON A CONTROI PANEI
}

\section{J. R. Beeler}

\begin{abstract}
This memorandum is an outline of the principles and methods employed by 5100 Human Engineering Personnel in consultation on test equipment panel layout. The process of control panel layout is partially formalized with particular emphasis on test equipment panels. An experimental method is proposed for selecting an optimum panel layout. The essential role of experimentation is pointed out. The optimal layout for a nonrepetitive procedure is deduced and generalized to give methods of layout solution for the general repetitive procedure.
\end{abstract}

\section{LEGAL NOTICE}

This report was prepared as an account of Government sponsored work. Neither the United States, nor the Commission, nor any person acting on behalf of the Commission:

A. Makes any warranty or representation, express or implied, with respect to the accuracy, completeness, or usefulness of the information contained in this report, or that the use of any information, apparatus, method, or process disclosed in this report may not infringe privately owned rights; or

B. Assumes any liabilities with respect to the use of, or for damages resulting from the use of any information, apparatus, method, or process disclosed in this report.

As used in the above, "person acting on behalf of the Commission" includes any employee or contractor of the Commission to the extent that such employee or contractor prepares, handles or distributes, or provides access to, any information pursuant to his employment or contract with the Commission. 


\section{DISCLAIMER}

This report was prepared as an account of work sponsored by an agency of the United States Government. Neither the United States Government nor any agency Thereof, nor any of their employees, makes any warranty, express or implied, or assumes any legal liability or responsibility for the accuracy, completeness, or usefulness of any information, apparatus, product, or process disclosed, or represents that its use would not infringe privately owned rights. Reference herein to any specific commercial product, process, or service by trade name, trademark, manufacturer, or otherwise does not necessarily constitute or imply its endorsement, recommendation, or favoring by the United States Government or any agency thereof. The views and opinions of authors expressed herein do not necessarily state or reflect those of the United States Government or any agency thereof. 


\section{DISCLAIMER}

Portions of this document may be illegible in electronic image products. Images are produced from the best available original document. 
$r .$.

2

\section{THIS PAGE WAS INTENTIONALLY LEFT BLANK}


TAELE OF CONTENTS

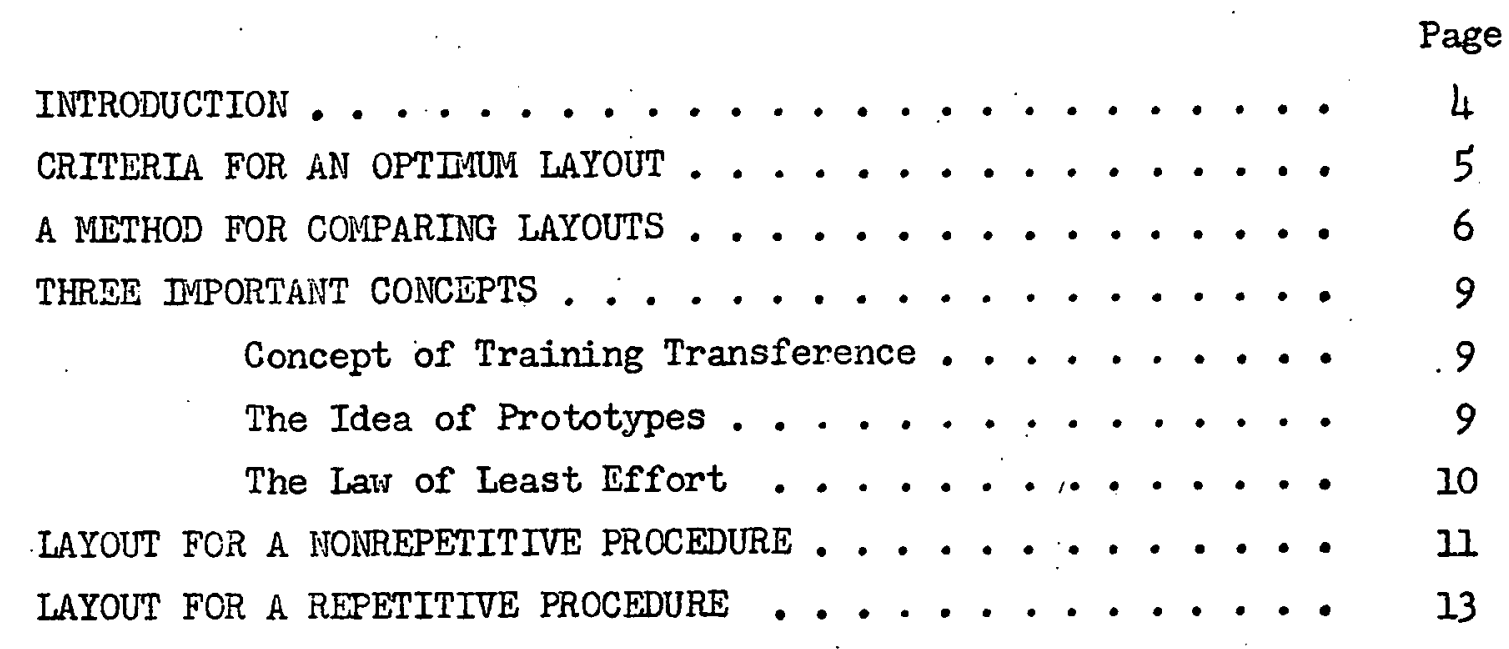




\section{INTRODUCTION}

This memorandum deals with test equipment panel layout, i.e., the most advantageous way to place control elements on a test panel. Three psychological concepts, which seem to be of fundamental importance in panel layout, are discussed. Using these fundamental concepts and the results of two classes of experiments, we then deduce the basic rules, 'in the large,' for panel layout with respect to increasing operational efficiency. In essence the frequently subconscious, intuitive process of making layout decisions will be partially formalized and this decision process will be converted into an ordered sequence of conscious steps, governed by a definite set of fundamental principles.

The reader will find no information in this paper concerning optimal design of individual control elements -- we deal here exclusively with the most advantageous way to arrange a set of given control elements upon a panel of given size and shape for a given procedure. The discussion is restricted to panel layout, 'in the large,' so to speak. Further, no corments are made on whether a certain test is needed, or on a way by which one can determine whether a test is needed. (The technique for deciding whether or not a test is needed has been worked out and will be discussed in a subsequent memorandum.) ${ }^{*}$ It is important that the reader realize that the domain to be covered here is a restricted one -- this realization will go a long way in helping him through the discussion. In discussing the material presented here with both Sandia Corporation and Military people, we have found that they have tended to imagine that the ideas covered in this memorandum vere supposed to include all factors and details of panel design; only layout is covered here.

* A Criterion for Test Procedure, Technical Memorandum 166-55-5I, by J.R. Beeler. 
First of all the goal in a test procedure will be set up. From a military viewpoint a weapon test should satisfy the following requirements:

1. If the test is run in isolation, i.e., widely separated in time frow other test runs, the time required to perform the test should be a minimum.

2. If the test is run in isolation, the number of human errors should be a minimum.

3. If the test is repeated over a given extended period of time, with a small time separation between test runs, the time per test should be a minimum.

4. If the test is repeated, as above, the number of human errors per test should be a minimum.

5. The time required to train an operator should be a minimum.

In this memorandum the satisfaction of the above requirements will be taken as the criterion for an optimum panel layout. On the surface the requirements seem to be clearly stated. However, if they are observed critically one sees that the minima, mentioned in the requirements, have not been defined operationally, i.e., one is not told how to go about getting numerical values for the minima. The answer we will give to this question may not be completely soul-satisfying because of its relative nature. In this paper the panel layout problem is assumed to be one in which we are given the panel size and shape, the number, size and type of control elements to be placed on the panel and a procedure (a set of instructions describing how and when each control element is to be used) which we must follow. Given all this we will attempt to devise an arrangement of control elements which will satisfy the five time and error requirements. The principles, which we will develop later in the discussion, that guide us toward an appropriate layout, are not refined enough to point directly to a single best arrangement. Rather, they enable us only to locate a region in which the best layout must lie. Once we know what this region is we must proceed by experiment. 


\section{$-6-$}

\section{- A METHOD FOR COMFARING ILAYOUTS}

Several layouts, which do not violate the basic principles are devised and the best layout is determined by experiment. The minimum referred to in a particular one of the five requirements is the minimum experimental value of the characteristic, associated with the requirement, over all the different layouts devised as allowable solutions. The characteristics are, of course:

1. The time required to run the test in isolation,

2. The number of human errors which occur when the test is run in isolation,

3. The time per test when the test is repeated over an extended period of time,

4. The number of human errors per test when the test is repeated over an extended period of time, and

5. The time required to train an operator to mun the test.

In general no one layout will exhibit characteristic-values which fit the minima exactly, and one is confronted with the problem of deciding which layout exhibits characteristic-values which come closest to satisfying all five minima. This determination involves the knowledge of exchange factors among the five characteristics, and a clean-cut solution is not possible in general, i.e., no one knows what all the exchange factors are. If the layouts are such that the characteristic curves do not cross, the determination of the best layout is straightforward. The determination is also straightforward if either crossing exists for only upper-lying characteristic curves or occurs in low-lying characteristic curves which differ only a small amount among themselves.

A clarifying example may be in order here. Suppose one has three layouts $I_{1}, I_{2}$, and $I_{3}$. By experiment one can determine the characteristics

$\mathrm{C}_{1}=$ time for the isolated test,

$\mathrm{C}_{2}=$ number of human errors for the isolated test,

$\mathrm{C}_{3}$ = average time per test in the repeated situation, 
$\mathrm{C}_{4}=$ average number of human errors per test in the repeated situation, and

$\mathrm{C}_{5}=$ time required to train an operator for each layout. The set of characteristics

\begin{tabular}{l|rrr} 
& $I_{1}$ & $I_{2}$ & $I_{3}$ \\
\hline$C_{1}$ & 30 & 25 & 20 \\
$C_{2}$ & 3 & 3 & 0 \\
$C_{3}$ & 40 & 38 & 30 \\
$C_{4}$ & 4 & 3 & $I$ \\
$C_{5}$ & 60 & 50 & 40
\end{tabular}

represents noncrossing characteristics. The set of characteristics

\begin{tabular}{r:rrr}
$\vdots$ & $I_{I}$ & $I_{2}$ & $I_{3}$ \\
\hline$C_{1}$ & 30 & 30 & 20 \\
$C_{2}$ & 3 & 2 & 15 \\
$C_{3}$ & 40 & 45 & 30 \\
$C_{4}$ & 4 & 2 & 6 \\
$C_{5}$ & 60 & 65 & 70
\end{tabular}

represents crossing characteristics. The characteristic curves for these two cases are plotted in Fig. 1. In the first case $\mathrm{L}_{3}$ achieves the minimum for each characteristic and is clearly the best layout. In the second case crossing occurs and one needs to know the exchange factors among the characteristics in order to determine the best layout.

For tactical employment, other things being equal, a high reliability is to be preferred over a large firing rate. This preference is based on the characteristics of one- and two-hit kill criteria duels. While the duel model is not an entirely appropriate analogue for all instances of warfare let us assume it fits the main features of a tactical engagement. The crossing-characteristics, plotted in Fig. I, are reproduced för convenience . in Table $I$. 

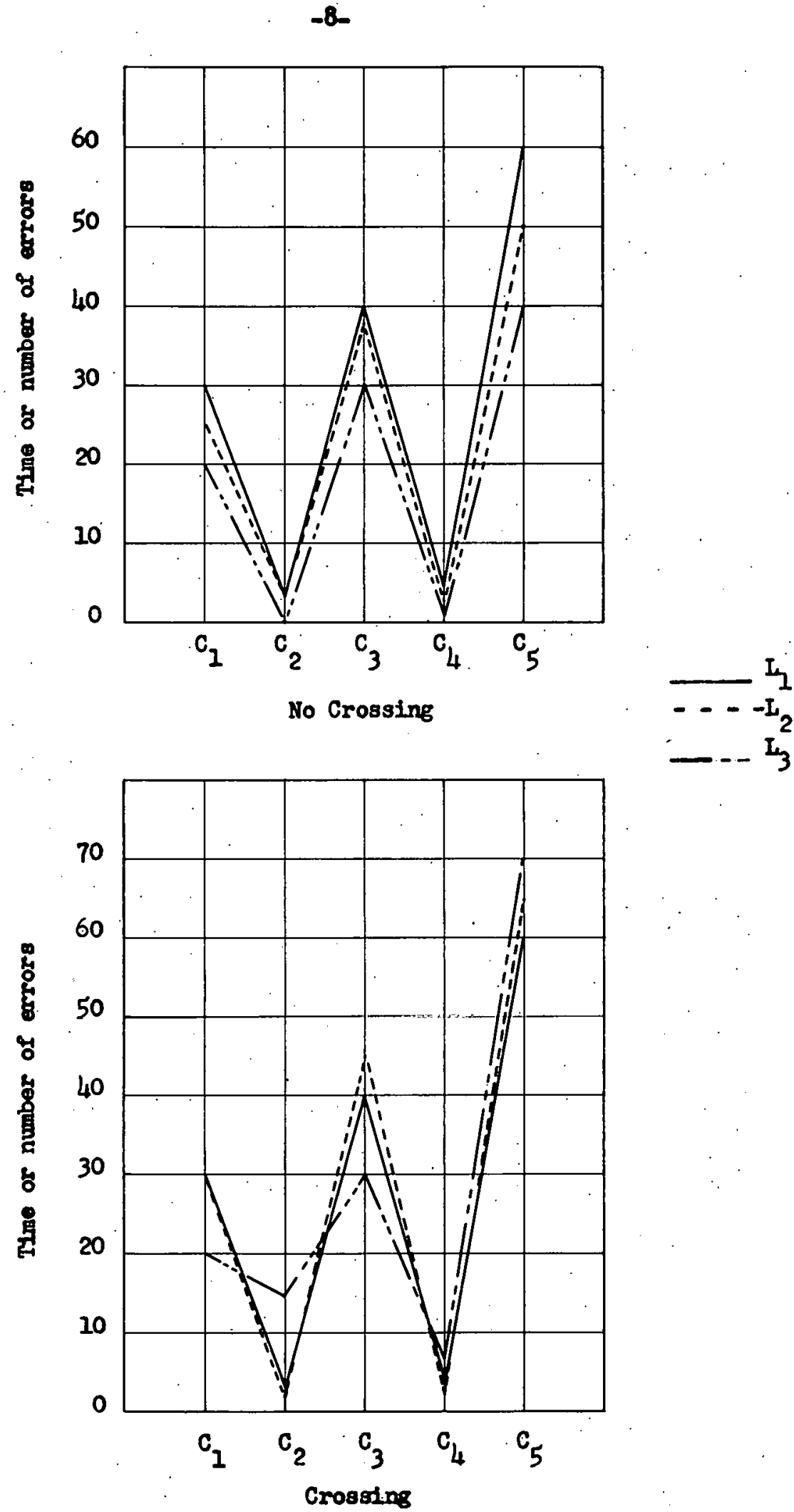

F18. 1. Charactorlstic Curves 


\section{ㅇ-}

TABLE I

Crossing - Characteristics

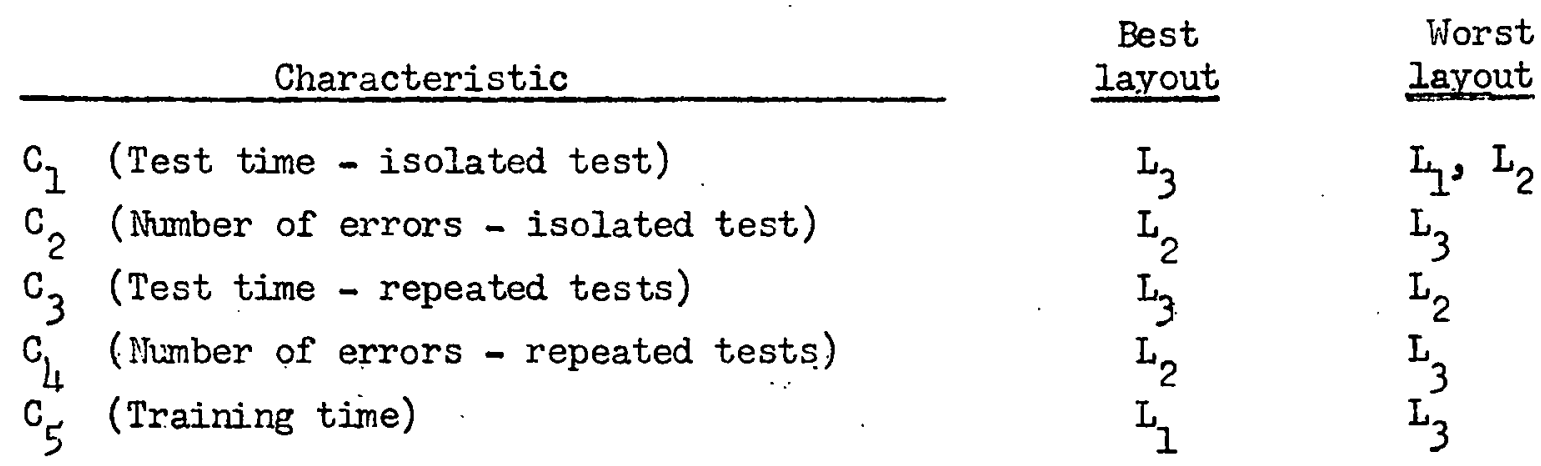

Table I shows that layout $\mathrm{I}_{2}$ allows 50 percent of the number of errors allowed by $L_{1}$ and only 30 percent of the number of errors allowed by $\mathrm{L}_{3}$. Hence $I_{2}$ is favored because of the higher reliability possible. In this instance simply knowing the direction in which the exchange goes (i.e., a high reliability is preferred over a large firing rate), is enough for a decision. The differences in training time are not significant. One needs to distinguish between crossing originating from layout sources per se and that originating from individual control element sources. The occurrence of crossing may not be caused by faulty layout, but rather by faulty design of some individual control element. If, in a layout problem, one cannot seem to eradicate crossing, it may mean that the given procedure or type of control elements ought to be changed. 
Three concepts can be taken as the basis for deciding how to satisfy the time and error requirements which constitute the goal of this study.

Concept of Training Transference

In learning and problem solving situations, it has been found that a person learns to perform a set of actions or to solve a problem in the shortest time if he follows a sequence of successively more complex and/or difficult behavior patterns,

$$
B_{1}, B_{2},-\cdots B_{n},-\cdots,
$$

which converge in complexity and structure to the desired behavior, where the governing rule of performance for behavior $B_{n}$ is an extension of the rule for the preceding behavior $B_{n-1}$. In this process the individual 'transfers' his capability to behave in an established pattern $B_{n-1}$ to a more difficult but similarly structured pattern $B_{n}$. This method is of course the traditional procedure for scientific investigation.

The Idea of Prototypes

Certain well-entrenched habits and bits of lmowledge are common to all of us (in a given society). He will call these common habits and pieces of knowledge Prototypes, as they are 'first' quantities in the sense that most of them are available to us for use on almost a conditioned reflex basis. They are not instincts; all of them have been learned, and in most cases learned early in life and constantly reinforced by repeated use. A few prototypes which will be used in this paper are:

1. The knowledge of alphabetical order, $\dot{A}, \mathrm{~B}, \mathrm{C},--$

2. The knowledge of numerical order, $1,2,3,--$

3. The knowledge of reading and writing order (left to right) and the habit of performing these activities.

4. The knowledge that if one wants to move an object in a given direction the most appropriate force is one in the direction of the desired motion. 
The Law of Least Effort

of all the ways to reach a given goal, which an individual can imagine for himself, he will choose the behavior mode which in his opinion requires the least amount of effort. It does not necessarily follow that the chosen mode is the most efficient in terms of energy expenditure. Formally this law is patterned after the Law of Least Action in physics. In physics one can precisely define Action, and the Principle of Least Action can be exactly applied to individual cases. In psychology one cannot precisely define Effort or write down the set of imagined behaviors an individual will construct for himself. Hence, for quantitative purposes, the law of least effort must be used in a statistical sense. That is, one tests a large number of people with respect to a given 'goal' and observes the different types of behavior exhibited, and their frequencies. One can then find that particular type(s) of behavior(s) was considered, by the population type tested, to require the least effort in the majority of instances. This procedure will lead to some insight concerning the nature of ' effort,' for the particular goals concerned.

These three concepts are vell known but not frequently used. The reason for their being ignored, in practice, is perhaps explained by the third concept, i.e., the Law of Least Effort. In the particular work of panel layout, for example, a designer has built up for himself a repertoire of 'things to do,' in the face of different problems he meets. "Many of these 'things to do' are genuine solutions to panel layout problems, but a few are more nearly just design cliches. In some instances, a good idea which comes to mind is discarded because it would require a new framework for thinking. 
If one applies the concepts of Least iffort, Transference, and Prototypes to the panel layout problem, one can construct some simple and important models. These models are based upon the idea of repetitive and non- . repetitive procedures. This idea is best illustrated by example. Suppose one is given the following procedure:

1. Turn switch A to ON

2. Set dial $D_{1}$ to $S_{1}$

3. Set dial $\mathrm{D}_{2}$ to $\mathrm{S}_{2}$

This is an example of a nonrepetitive procedure -- no control element is used more than once. The following procedure is an example of a repetitive procedure:

1. Turn switch A to ON

Light $I_{A}$ lights

2. Turn switch $B$ to ON

Light $I_{B}$ lights

3. Turn switch $B$ to $O F F$

Light $I_{B}$ goes out

4. Set dial D to $S$

Repetition occurs for switch $B$ and light $L_{B^{*}}$ Clearly one seldom encounters a purely nomrepetitive procedure. However, one observes that, in general, every procedure can be divided into parts which are nonrepetitive. This observation hints that although a procedure which is nonrepetitive in toto rarely occurs, the idea of a nonrepetitive procedure may be fruitful and so we will spend some time discussing the purely nonrepetitive procedure. Suppose one is given a purely nonrepetitive procedure. How should the control elements associated vith this procedure be arranged on the panel so that:

1. The procedure can be learned in the shortest time, and

2. The time required to go through the procedure is a minimum? 
The arrangement which most completely dereats our purpose is that of placing the control elements on the panel at random. Experiments show that both the learning and operating time are maximized by such a layout.* This leaves one direction of attack -- namely that of arranging the control elements in some nonrandom pattern. The experiments mentioned above also show that the time required to go through a nonrepetitive procedure decreases as the regularity of the control element arrangement increases. (One can deduce this qualitative result from the principles of Gestalt Psychology; no experimentation was really needed in this respect. The value of the experiments is in the quantitative information obtained. The experiments showed, for example, that the location time for 30 control element positions was decreased by a factor of 12 by the introduction of regular patterning, with respect to a random placement of. control element positions.) By the Principle of Transference one can reduce learning time by choosing an ordering pattern on the panel which is both close to some ordering pattern familiar to most individuals and at the same time corresponds, in space, to the order, in time, of the steps in the procedure. Three simple possibilities suggest themselves: The first is an arrangement of the control elements in rows, with $\mathrm{N}_{i}$ elements in the $i{ }^{\text {th }}$ row, such that in going from left to right along the first (upper) row we encounter, in sequence, the control elements corresponding to the first $\mathbb{N}_{1}$ steps in the procedure; the next $\mathrm{N}_{2}$ steps in following the second row from, left to right, and so on until all control elements and procedure steps are exhausted. The second possibility is to arrange the control elements in columns according to the same scheme. The third possibility is to arrange them in a circular sequence running clockwise. The first possibility is based on the Prototype activity of reading and writing, the second upon a -90-degree rotation of the reading and uriting Prototype, and the third

* See $\AA$ Study of Location Times for Positions Arranged on a Panel in a Random and an Ordered Manner, Technical Memorandum 92-55-51, by J. R. Beeler, May 25, 1955. 
upon the clock-face prototype. By the Law of Least Effort one wolld be inclined to reject the second possibility. The third one is also liable to rejection, not for its 'unnaturalness' but because it does not allow efficient utilization of panel space. Hence we will select the left to right row arrangements and talk in terms of it. (In particular situations, one of the other arrangements may be appropriate and one should not conclude the left to right; row arrangement is in general preferable. No clean cut experimental evidence for the advantage of row layout over column layout has been produced to date.)

\section{IAYOUT FOR A REPETITIVE PROCEDURE}

Our ideas concerning the general layout in the case of a nonrepetitive procedure can be extended to help in the layouts for repetitive procedures. The extension is performed as follows: Some repetitive procedures can be decomposed into groups of steps $G_{1}, G_{2},--, G_{n}$ such that steps in each group follow in a nonrepetitive sequence. For example, consider the procedure outlined in Table II.

TABLE II

An Example of How a Repetitive Procedure Can Be Decomposed Into Nonrepetitive Groups

\begin{tabular}{|c|c|c|c|}
\hline Group & Step & Operation & Associated Function \\
\hline $\mathrm{G}_{1}$ & 1 & $\mathrm{~S}_{1}$ to $\mathrm{ON}$ & DC power switch \\
\hline & 2 & $\mathrm{~s}_{2}$ to $\mathrm{ON}$ & Circuit changing switch \\
\hline & 3 & $\mathrm{~S}_{3}$ to $\mathrm{ON}$ & AC power switch \\
\hline$G_{2}$ & 4 & $\mathrm{~s}_{4}$ to $\mathrm{ON}$ & Meter shunt switch \\
\hline & 5 & $\begin{array}{l}\text { Read meter M } \\
\text { (meter should read } 0 . \text { ) }\end{array}$ & -- \\
\hline$G_{1}$ & 6 & $s_{5}$ to $\mathrm{ON}$ & Circuit changing switch \\
\hline & 7 & $\mathrm{~S}_{2}$ to $\mathrm{OFF}$ & Circuit changing switch \\
\hline $\mathrm{G}_{2}$ & 8 & $\mathrm{~S}_{3}$ to $\mathrm{OFF}$ & AC power switch \\
\hline & 9 & $\mathrm{~S}_{4}$ to $\mathrm{OFF}$ & Meter shunt switch \\
\hline & 10 & $\begin{array}{l}\text { Read meter } M \\
\text { (meter should read } 4 . \text { ) }\end{array}$ & -- \\
\hline
\end{tabular}


TABLE II (Cont'd)

\begin{tabular}{|c|c|c|c|}
\hline Group & Step & Operation & Associated Function \\
\hline $\mathrm{G}_{1}$ & 11 & $\mathrm{~S}_{1}$ to $\mathrm{OFF}$ & DC power switch \\
\hline \multirow{4}{*}{$\mathrm{G}_{2}$} & 12 & $S_{2}$ to $O N$ & Circuit changing switch \\
\hline & 13 & $\mathrm{~S}_{3}$ to $\mathrm{ON}$ & AC power switch \\
\hline & 14 & $s_{4}$ to ON & Meter shunt sritch \\
\hline & 15 & $\begin{array}{l}\text { Read meter } M \\
\text { (meter should read }\end{array}$ & - \\
\hline \multirow[t]{2}{*}{$G_{1}$} & 16 & $s_{5}$ to $O F F$ & Circuit changing switch \\
\hline & 17 & $\mathrm{~S}_{2}$ to $\mathrm{OFF}$ & Circuit changing switch \\
\hline \multirow{3}{*}{$G_{2}$} & 18 & $\mathrm{~S}_{3}$ to $\mathrm{OFF}$ & AC power switch \\
\hline & 19 & $\mathrm{~S}_{4}$ to $\mathrm{OFF}$ & Meter shunt switch \\
\hline & 20 & $\begin{array}{l}\text { Read meter } M \\
\text { (meter should read }\end{array}$ & --- \\
\hline
\end{tabular}

This procedure is seen to be divisible into the two groups

$$
\begin{aligned}
& G_{1}: S_{1} \text { and } S_{5} \text { steps } \\
& G_{2}: S_{2}, S_{3}, S_{4} \text { and } M \text { steps. }
\end{aligned}
$$

The functions associated with each step have been listed to contrast two modes of panel layout. The layout in Fig. 2 follows the frequently used scheme: 'meters in the middle and power switches on one side.' The layout in Fig. 3 follows the method suggested above, namely, decomposition into nonrepetitive groups and a space-ordering, of the control elements on the panel associated with the steps in each group, parallel to the procedure ordering, in time, for the associated steps. The two switches on the extreme left 'set up' the circuitry for performances of the $G_{2}$ group.

Some repetitive procedures, which cannot be reduced to a nonrepetitive procedure by the afore-mentioned scheme, can be civilized, so to speak, by another approach. This class of procedures is that in which the repeated interjection of the same $\hat{i}$ ew steps is inposed upon an underIying nonrepetitive procedure. In this case the procedure can be reduced, 
$-16$

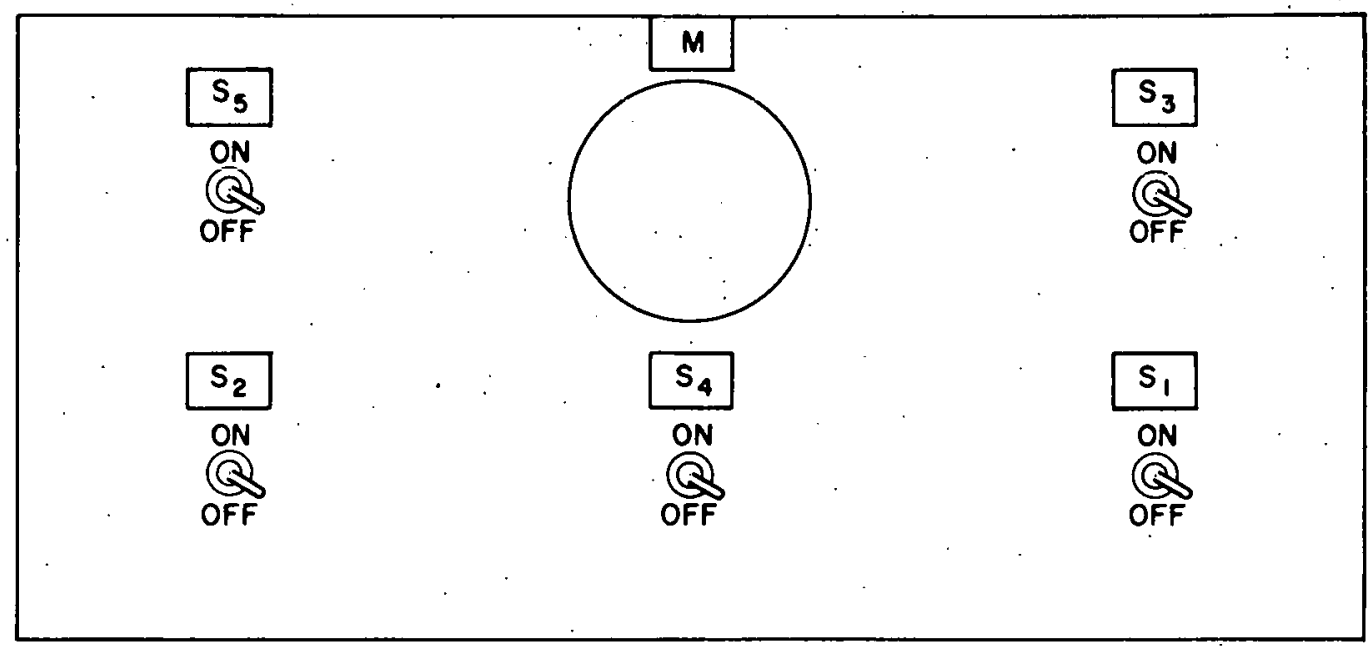

Fig. 2. 'Meter-in-the-middle' Layout

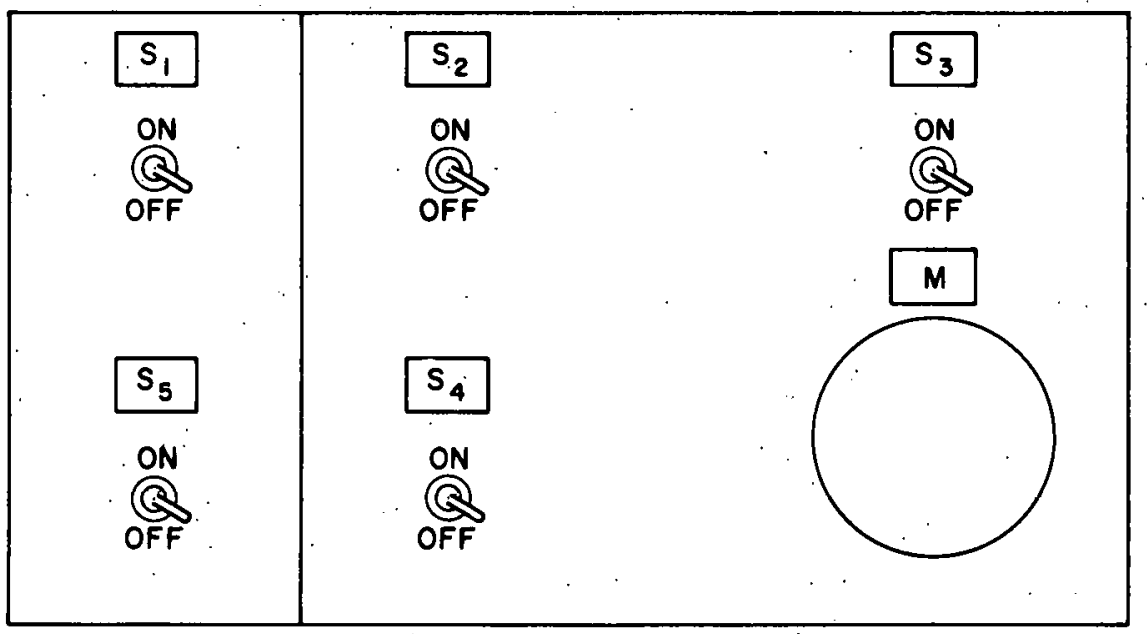

Fig. 3. Leyout by the Decomposition Method

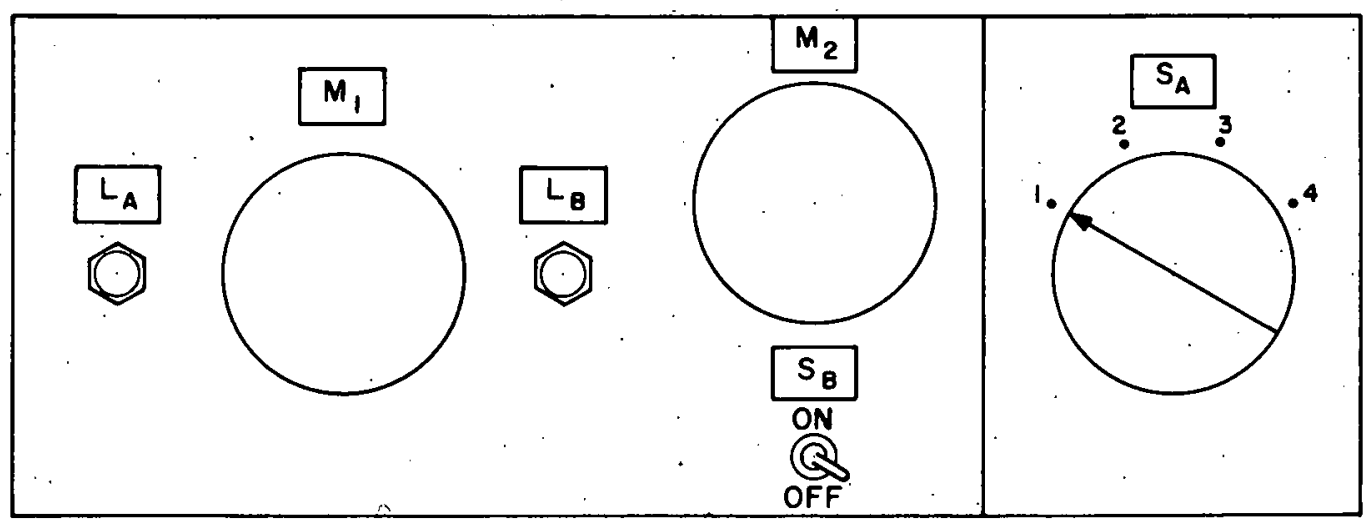

Flg. 4. Layout by the Extraction Method 
in effect, to a nonrepetitive procedure by placing the few often used control elements, corresponding to the steps responsible for the interjected repetition, on either the extreme left or right side of the panel and filling the vacant middle ground with a row arrangement corresponding to the nonrepetitive procedure. This will be called the extraction method. Consider the following simple example: Let the procedure be,

I. Set switch A to POS 1

$I_{A}$ lights

2. Set switch A to POS 2

Meter $M_{1}$ reads $V_{1}$ volts

3. Set switch A to POS 3

$I_{B}$ lights

4. Set switch A to POS 4

5. Operate switch B

Meter $M_{2}$ reads $I_{2}$ amps

Using the extraction method one arrives at a panel show in Fig. 4.

If one finds that a procedure cannot be rendered nonrepetitive by the use of artifices similar to the ones described, one way out is to revise the procedure so that it can be converted. This can mean a change in the functional design of the equipment, i.e., how the components are interrelated, but this is not necessarily the case. So long as the functional reliability of the equipment is not seriously diminished, a very valuable contribution can be made in the functional design if it is such that a selector switch, whose position sequence. isets up' the circuitry for succeeding procedure steps, can be used. This does much to increase operational reliability. This being done the designer will have little trouble in producing a panel layout which allows efficient operation and a minimal training time. One trouble occurs in the case of long procedures: A single selector switch cannot physically accommodate all the steps. This of course can be circumvented by using a sequence of set-up switches. It has been found that a selector switch ought not have its individual setting positions less than 20 degrees apart and that not more than 180 degrees of rotation should be used for most efficient operation. This 
rule came from ifr. M. Warrick of the Wright Field Aero-Medical Laboratory. If the test equipment designer can construct a scheme which gives rise to a procedure which can be made effectively nonrepetitive, he is contributing greatly toward a much more efficient piece of equipment, from the operational standpoint.

J. R. BEELER - 5123

Case No. 477.00

August 1, 1955 


$$
1-18
$$

THIS PAGE

\section{WAS INTENTIONALLY \\ LEFT BLANK}


